\title{
LUSI CXI Detector Stage \#1 Alignment and Motion
}

D. Schafer, Mechanical Engineer

SLAC, Stanford, CA 94025, USA

\begin{abstract}
Detector stage DS1 needed alignment adjustments in the $\mathrm{Y}$ axis for the $\mathrm{Z}$ axis (parallel to beam) to run true to the vacuum chamber. To achieve correct alignment the stage was shimmed between two plates in the vacuum chamber. This report describes the correction and presents the resulting measured travel.
\end{abstract}

\section{BACKGROUND}

Stage was built to satisfy PRD: SP-391-000-28 and ESD: SP-391-000-70. It has six degrees of freedom. Five are achieved with manipulators attached to the vacuum chamber and the sixth (along beamline, Z) with a 20" travel linear stage inside the vacuum chamber. Shown below in Figure 1 is the top view of the CXI detector stage, SLAC drawing SA-391-520-00.

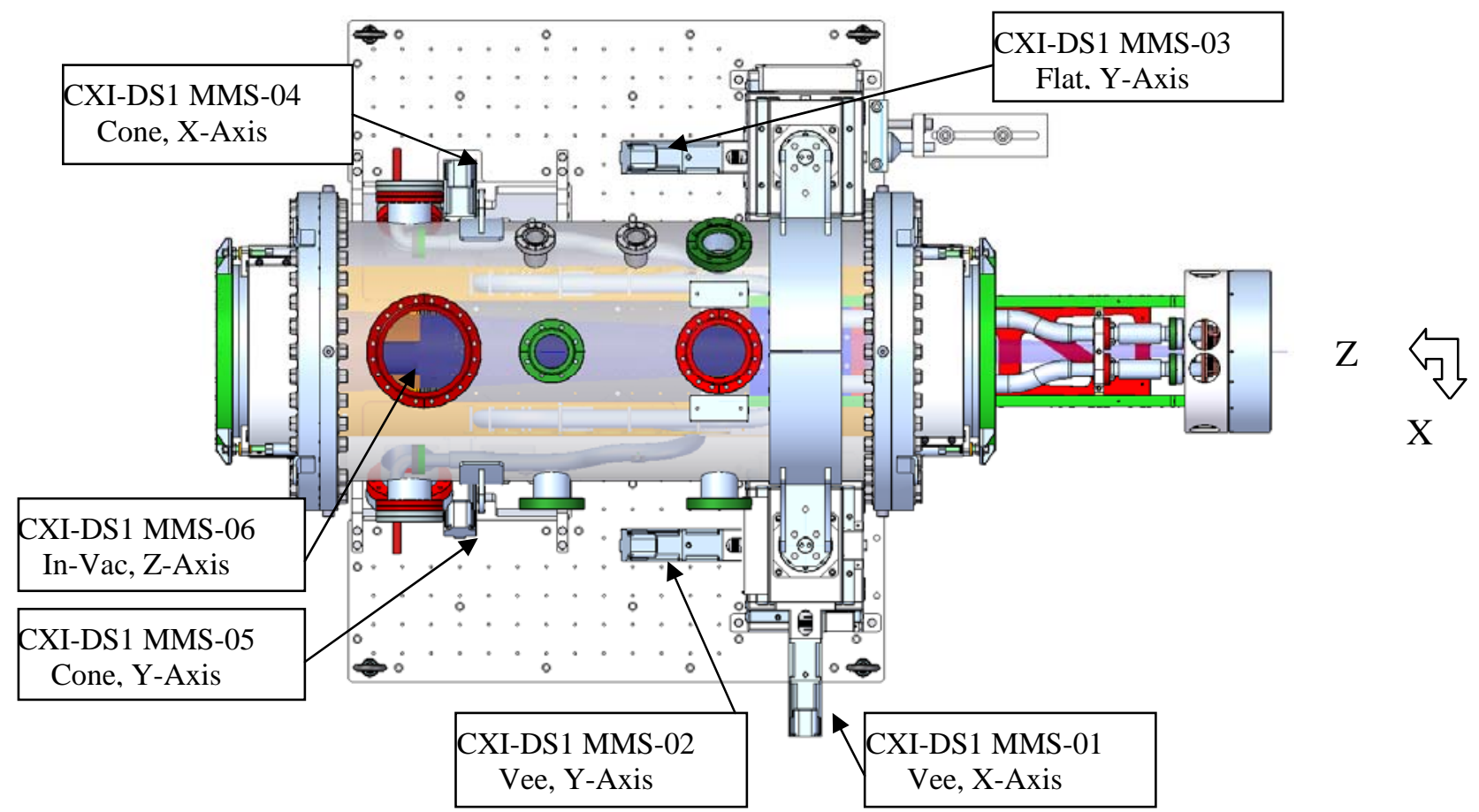

Figure 1: Detector Stage (Assembly SA-391-520-00)

\section{DESCRIPTION OF PROBLEM}

As the $\mathrm{Z}$ axis in vacuum stage extends out of the chamber it was traveling with a downward slope relative to the beam axis. The error is represented by the RED line in Figure 2 below. In the 20" of $\mathrm{Z}$ travel it went down 0.140 ” in Y, passing through the ideal axis. The BLACK line represents the ideal path (true to chamber) and the BLUE line is the corrected path ( 0.065" above ideal, as close to parallel as can be easily achieved). The out of vacuum stages (the other 5 axes of motion) have a limited travel and can correct a translation offset much easier than the measured pitch error. 


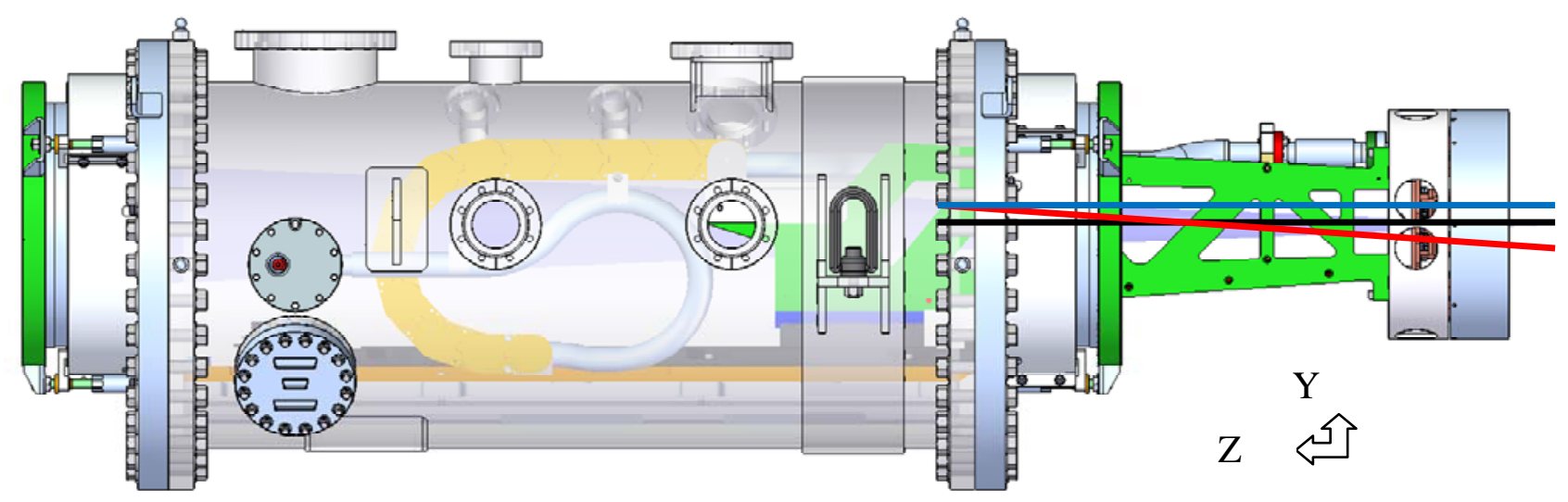

Figure 2: Detector Stage Chamber (Assembly SA-391-520-02), Side View

Showing Skew Through Z Travel

\section{SOLUTION}

\subsection{Shims}

To correct the angle of the $\mathrm{Z}$ axis stage shims of varying thicknesses were tried in the location shown in Figure 3 below. The final shim was a 0.060 " thick stainless steel washer on each side of the front of the chamber, on top of the bosses on the "Optical Bench" SLAC drawing number PF-391-520-56 (grey plate labeled 1, below). This would move the front of the plate on top of the shims (PF-391-520-09, orange plate labeled 2, below).

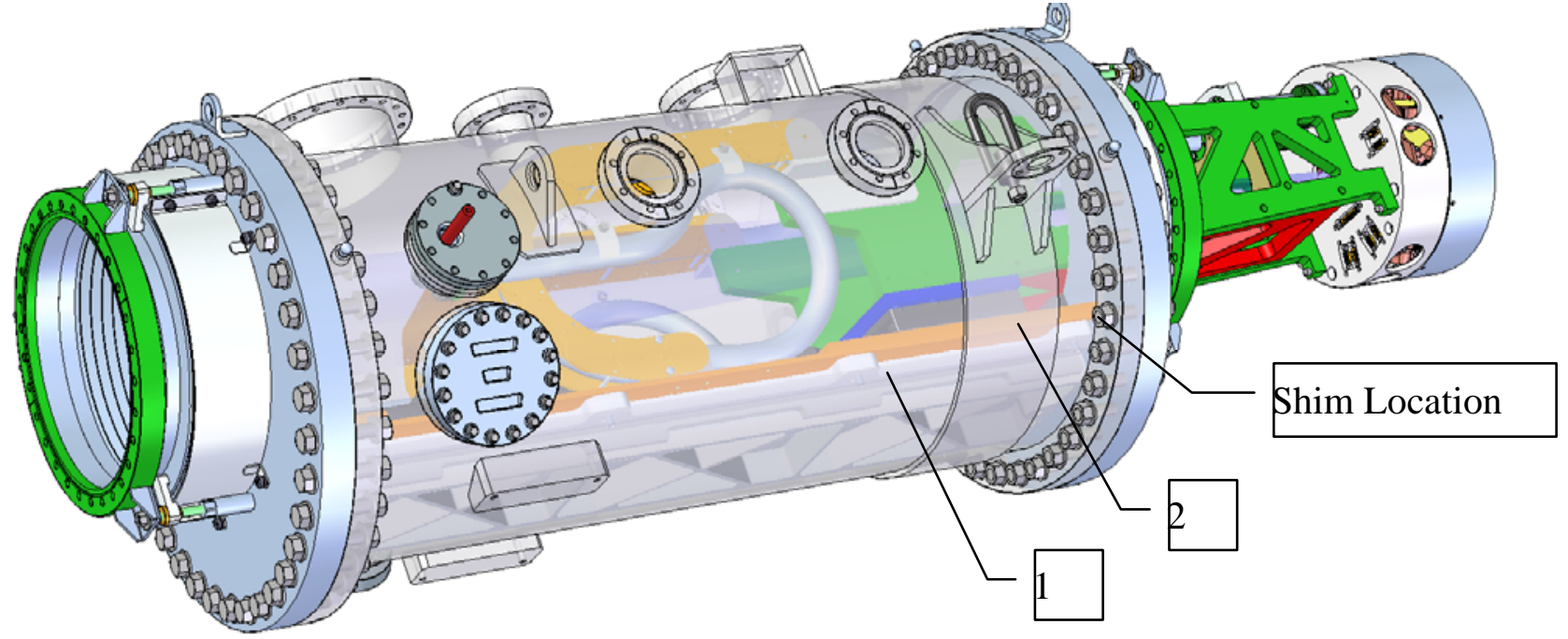

Figure 3: Detector Stage Chamber (Assembly SA-391-520-02) Showing Shim Location Detail 


\subsection{Adjusted motion profile}

The shim corrected motion is shown below in Table I. Data was taken by the SLAC Alignment group using their Faro laser tracker device measuring holes on the Interface ring of the CS-PAD detector. The nominal locations of these holes are noted in Table I relative to the chamber center (determined by Alignment using the 22 1/8" wire seal flanges on either end of the chamber). Since the chamber was aligned to the beam as well, this also represents the travel relative to beam. Figure's 4 through 9 show the data from Table I graphically.

Table I: SLAC Alignment Data

\begin{tabular}{|c|c|c|c|c|c|c|c|c|c|}
\hline \multirow[t]{2}{*}{ Name } & \multirow[b]{2}{*}{$\Delta \mathrm{Z}$ [in] } & \multirow{2}{*}{\begin{tabular}{|l} 
Plus $\mathrm{X}$ \\
$\Delta \mathrm{X}[\mathrm{in}]$ \\
\end{tabular}} & \multirow[b]{2}{*}{$\Delta \mathrm{Y}[\mathrm{in}]$} & \multirow[b]{2}{*}{$\Delta \mathrm{Z}[\mathrm{in}]$} & \multirow{2}{*}{$\begin{array}{l}\text { Minus } X \\
\Delta X[\text { in }] \\
\end{array}$} & \multirow[b]{2}{*}{$\Delta \mathrm{Y}[\mathrm{in}]$} & \multirow[b]{2}{*}{$\Delta \mathrm{Z}[\mathrm{in}]$} & \multicolumn{2}{|l|}{ Bottom (-Y) } \\
\hline & & & & & & & & $\Delta \mathrm{X}[\mathrm{in}]$ & $\Delta \mathrm{Y}[\mathrm{in}]$ \\
\hline DO & $\mathrm{NaN}$ & $\mathrm{NaN}$ & $\mathrm{NaN}$ & -23.974 & -4.088 & 2.910 & -23.983 & -2.884 & -3.988 \\
\hline D1 & $\mathrm{NaN}$ & $\mathrm{NaN}$ & $\mathrm{NaN}$ & -24.974 & -4.085 & 2.910 & -24.983 & -2.882 & -3.987 \\
\hline D2 & -25.988 & 2.829 & 4.112 & -25.974 & -4.075 & 2.911 & -25.984 & -2.882 & -3.988 \\
\hline D3 & -26.985 & 2.823 & 4.117 & -26.974 & -4.092 & 2.912 & -26.983 & -2.884 & -3.987 \\
\hline D4 & -28.001 & & & -27.976 & -4.084 & 2.908 & -27.984 & -2.884 & -3.987 \\
\hline D5 & -28.990 & 2.813 & 4.107 & -28.976 & -4.080 & 2.910 & -28.983 & -2.873 & -3.987 \\
\hline D6 & -29.989 & 2.821 & 4.111 & -29.976 & -4.084 & 2.909 & -29.983 & -2.873 & -3.985 \\
\hline D7 & -30.990 & 2.822 & 4.113 & -30.979 & -4.076 & 2.907 & -30.985 & -2.878 & -3.984 \\
\hline D8 & -31.989 & 2.822 & 4.114 & -31.978 & -4.069 & 2.912 & -31.985 & -2.879 & -3.983 \\
\hline D9 & -32.990 & 2.820 & 4.115 & -32.979 & -4.077 & 2.908 & -32.984 & -2.867 & -3.984 \\
\hline D10 & -33.989 & 2.824 & 4.116 & -33.979 & -4.077 & 2.905 & -33.983 & -2.866 & -3.984 \\
\hline D11 & -34.990 & 2.820 & 4.113 & -34.980 & -4.073 & 2.904 & -34.984 & -2.869 & -3.986 \\
\hline D12 & -35.991 & 2.818 & 4.113 & -35.982 & -4.067 & 2.905 & -35.984 & -2.877 & -3.987 \\
\hline D13 & -36.991 & 2.819 & 4.114 & -36.982 & -4.063 & 2.906 & -36.984 & -2.866 & -3.985 \\
\hline D14 & -38.012 & & & -37.987 & -4.059 & 2.898 & -37.985 & -2.875 & -3.987 \\
\hline D15 & -39.000 & 2.819 & & -38.983 & -4.070 & 2.903 & -38.985 & -2.875 & -3.990 \\
\hline D16 & -39.994 & 2.828 & 4.112 & -39.983 & -4.068 & 2.903 & -39.985 & -2.874 & -3.989 \\
\hline D17 & -40.995 & 2.826 & 4.110 & -40.983 & -4.068 & 2.905 & -40.985 & -2.863 & -3.987 \\
\hline D18 & -41.995 & 2.830 & 4.111 & -41.983 & -4.069 & 2.904 & -41.985 & -2.863 & -3.988 \\
\hline D19 & -42.997 & 2.831 & 4.108 & -42.986 & -4.070 & 2.899 & -42.986 & -2.866 & -3.990 \\
\hline & AVG: & 2.823 & 4.112 & & -4.075 & 2.906 & & -2.874 & -3.987 \\
\hline & NOMINAL: & 2.839 & 4.055 & & -4.055 & 2.839 & & -2.839 & -4.055 \\
\hline & AVG ERROR: & -0.016 & 0.057 & & -0.020 & 0.067 & & -0.035 & 0.068 \\
\hline
\end{tabular}

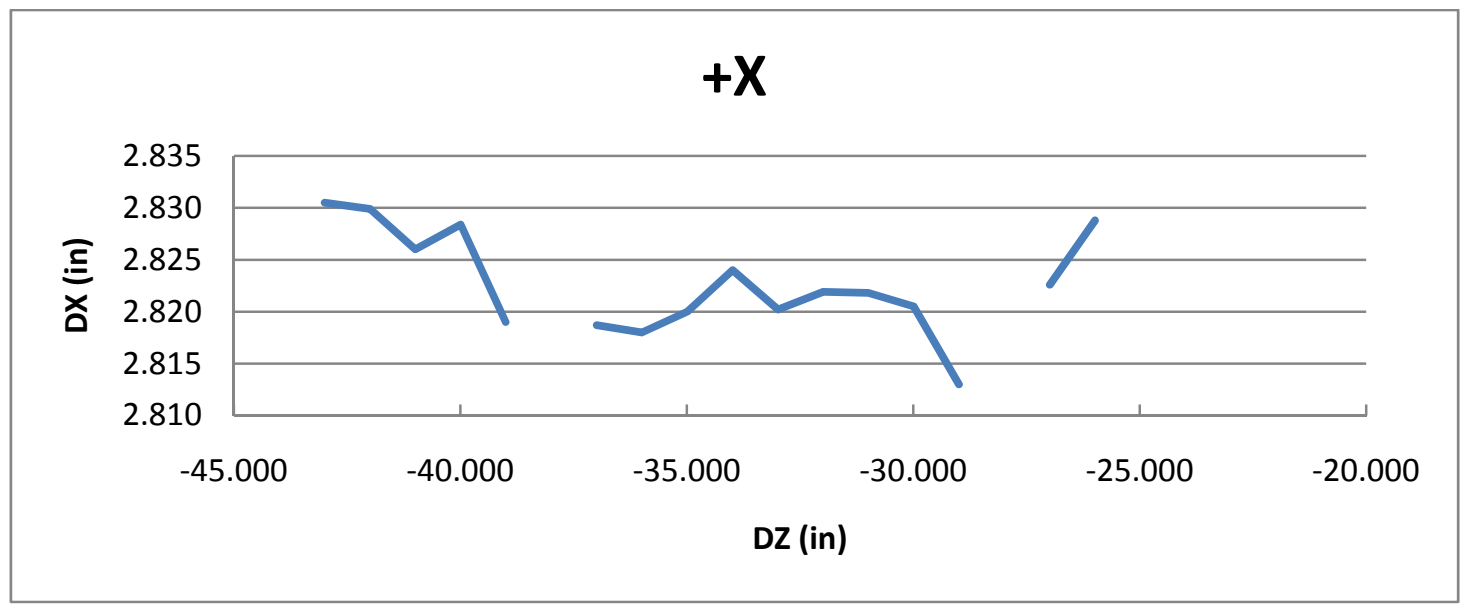

Figure 4: Plus X location on Interface ring, $\mathrm{X}$ coordinate data 


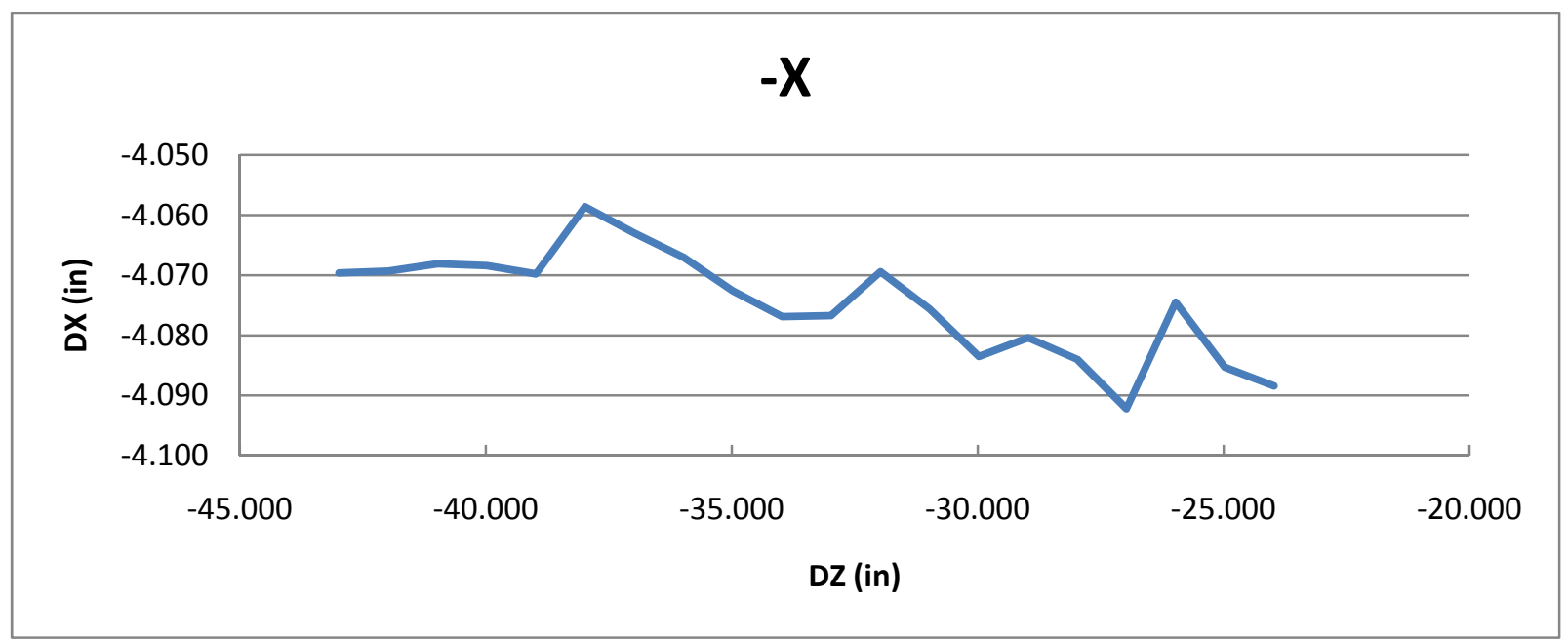

Figure 5: Minus $\mathrm{X}$ location on Interface ring, $\mathrm{X}$ coordinate data

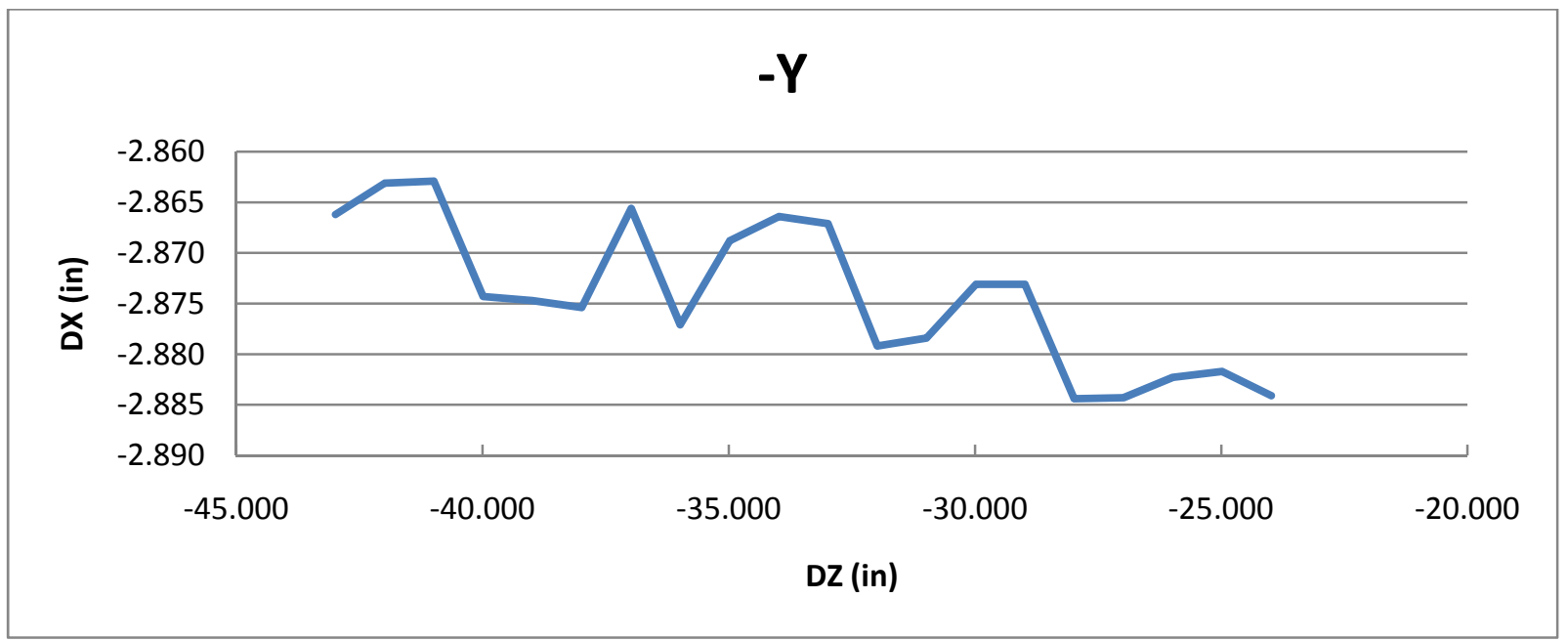

Figure 6: Bottom (-Y) location on Interface ring, X coordinate data

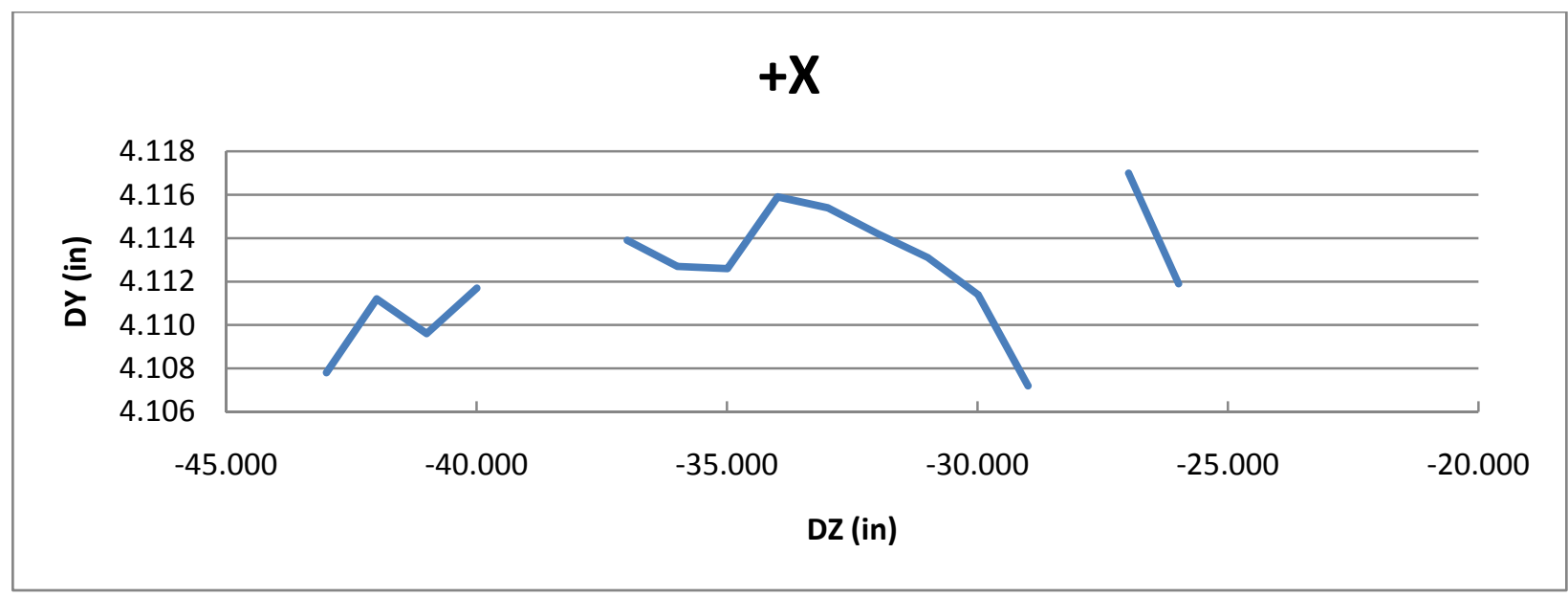

Figure 7: Plus X location on Interface ring, Y coordinate data 


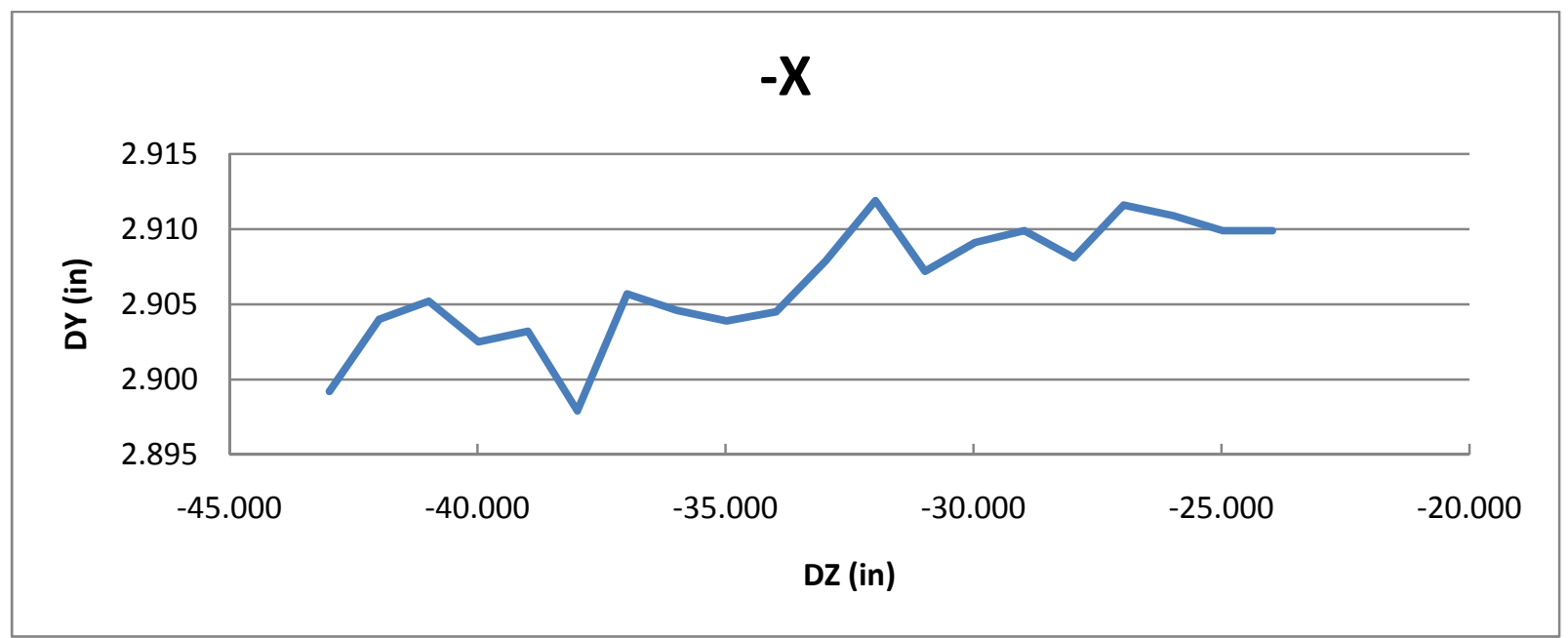

Figure 8: Minus X location on Interface ring, Y coordinate data

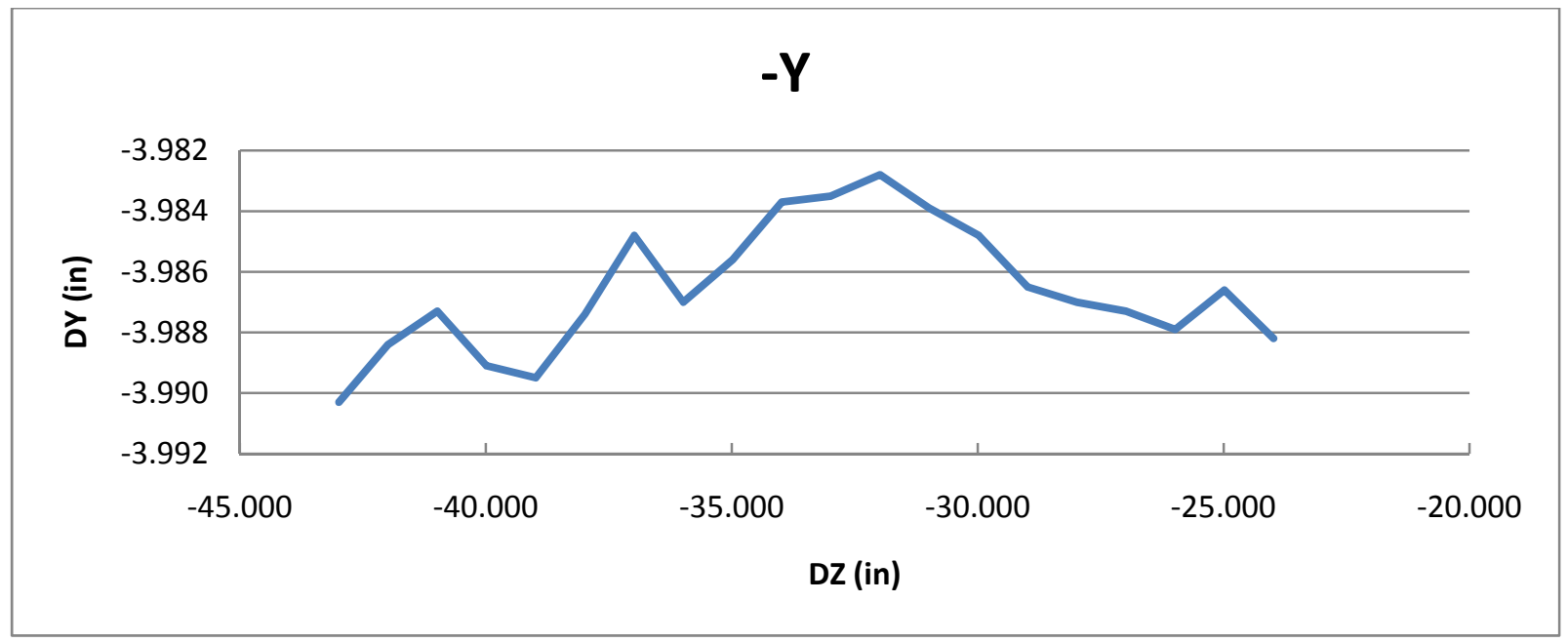

Figure 9: Bottom (-Y) location on Interface ring, Y coordinate data

\section{CONCLUSION}

$\mathrm{Z}$ Axis motion has been corrected to run relatively true to the chamber axis with a bias of $\sim .065$ ”. The measured irregularities can be canceled actively using the out-of-vacuum stages moving the chamber. 